\title{
Desastre da Samarco e políticas de saúde no Espírito Santo: ações aquém do SUS?
}

\author{
Samarco disaster and health policies in Espírito Santo
}

Frederico Viana Machado', Monika Weronika Dowbor², |gor Amaral2

DOI: 10.1590/0103-11042020E210

RESUMO O presente estudo buscou compreender as ações mitigadoras propostas como resposta ao impacto provocado pelo rompimento da barragem da Samarco na cidade de Mariana, Minas Gerais. Como parte de um estudo maior, este recorte enfoca as políticas públicas de saúde e as cidades de Colatina e Linhares, no estado do Espírito Santo. Por meio de métodos qualitativos, investigaram-se o arranjo político-administrativo que envolve a empresa Samarco, o Comitê Interfederativo (CIF), a Fundação Renova e os poderes públicos, interrogando sobre o papel dos atores na produção de medidas compensatórias e reparatórias. Foram utilizadas a análise de documentos, sobretudo, os relatórios disponíveis no site da Fundação Renova (de março de 2016 a maio de 2018), e sete entrevistas semiestruturadas com atores de referência nas duas cidades estudadas. A análise foi orientada pelo escopo teórico do ciclo de políticas públicas. Identificou-se uma estrutura político-administrativa formulada de forma nitidamente top down, com ênfase na etapa da formulação de políticas em detrimento da entrega de serviços e com pouca articulação entre os atores públicos e da sociedade civil na busca de solução de problemas de saúde.

PALAVRAS-CHAVE Planejamento em desastres. Saúde pública. Política pública.

\begin{abstract}
The present study sought to understand the mitigating actions proposed in response to the impact caused by the rupture of the Samarco dam in the city of Mariana, Minas Gerais. As part of a larger study, this section focuses on public health policies and the cities of Colatina and Linhares, in the state of Espirito Santo. Through qualitative methods, the political-administrative arrangement involving the company Samarco, the Interfederative Committee (CIF), the Renova Foundation and public authorities was investigated, questioning the role of the actors in the production of compensatory and remedial measures. Document analysis was used, especially the reports available on the Renova Foundation website (from March 2016 to May 2018), and seven semi-structured interviews with leading actors in the two cities studied. The analysis was guided by the theoretical scope of the public policy cycle. A clearly structured top-down political-administrative structure was identified, with an emphasis on the formulation of policies at the expense of service delivery and little articulation between public actors and civil society in the search for solutions to health problems.
\end{abstract}

KEYWORDS Disaster planning. Public health. Public policy.

1 Universidade Federal do Rio Grande do Sul (UFRGS) - Porto Alegre (RS), Brasil. fredvma@yahoo.com

2 Universidade do Vale do Rio dos Sinos (Unisinos) São Leopoldo (RS), Brasil. 


\section{Introdução}

O presente artigo analisa as ações mitigadoras propostas e executadas como resposta ao impacto provocado pelo rompimento da barragem da Samarco na cidade de Mariana, estado de Minas Gerais. Como parte de um estudo maior, este recorte enfoca as políticas públicas de saúde e as cidades de Colatina e Linhares, no estado do Espírito Santo. Por meio de métodos qualitativos, investigamos $o$ arranjo político-administrativo que envolve a empresa Samarco, o Comitê Interfederativo (CIF), a Fundação Renova e os poderes públicos, interrogando sobre a atuação desses atores na produção de medidas que visavam reparar os danos causados na saúde da população atingida, desde a formulação até a implementação, bem como suas interações com o setor municipal de saúde.

A relação entre saúde pública e emergências e desastres encontra amparo técnico e político em marcos internacionais de referência, tais como o Funções Essenciais da Saúde Pública (Fesp), sistematizado pela Organização PanAmericana da Saúde em 2002; o Regulamento Sanitário Internacional na Organização Mundial da Saúde de 2005; o Marco de Ação de Hyogo na Estratégia Internacional de Redução de Desastres de 2005; e, recentemente, o Marco de Sendai de 2015. Este último aprofunda essas relações expandindo a noção de 'desastre' e reconhecendo o papel das políticas de saúde na redução de riscos e enfrentamento às emergências e desastres. Entretanto, Londe $\mathbf{1}^{\mathbf{1}}$ analisa os manuais sobre emergência ou estado de calamidade pública da Secretaria de Defesa Civil e argumenta que "os impactos na saúde pública, em geral, são subvalorizados e classificados como 'desastres secundários"'1(538). Freitas ${ }^{2}$ aponta que os desastres são pouco pesquisados no âmbito da saúde coletiva brasileira.

Os impactos dos desastres na saúde pública são discutidos com suporte da Organização Pan-Americana da Saúde ${ }^{\mathbf{3} 4}$. Os efeitos dos desastres na saúde pública se dão em curto (mortalidade e feridos graves), médio (aumento de doenças) e longo prazo (processos depressivos e danos psicossociais) ${ }^{2}$. Embora no caso das cidades do estado do Espírito Santo, objeto desta análise, os equipamentos públicos de saúde não tenham sido danificados pelo desastre, os impactos na saúde pública foram muitos, de médio e longo prazo.

Os efeitos de médio e longo prazo exigem, ou deveriam exigir, a preparação das políticas e serviços de saúde para atender, prevenir e mitigar as diversas e complexas incidências de enfermidades, mas também processos psicossociais, tais como a depressão, perda de identidade social, coletiva e cultural por parte dos atingidos ${ }^{\mathbf{1}-4}$. Espera-se que a mitigação dos danos humanos reduza a gravidade de processos sistêmicos que se retroalimentam psicossocialmente, afetando o desenvolvimento e a economia local, a autonomia e os processos organizativos das comunidades, limitando o acesso a recursos e condicionando as possibilidades de recuperação e reconstrução.

No caso do desastre provocado pela Samarco, foi montado um arranjo institucional novo que consiste em entregar a realização de 'programas compensatórios e reparatórios' a um ente privado especialmente criado para isso, a Fundação Renova, conforme o Termo de Transação e Ajustamento de Conduta (TTAC) ${ }^{5}$. O Termo é um acordo jurídico firmado entre Executivo, Judiciário e a empresa causadora do desastre e prevê uma série de programas e medidas necessárias à compensação e recuperação dos danos socioeconômicos e socioambientais decorrentes. A condução dessas ações, de acordo com o TTCA, será fiscalizada e supervisionada pelo poder público ${ }^{5}$. Desse modo, as respostas aos problemas públicos são, ou deveriam ser, dadas por meio de um arranjo institucional que articula as diferentes esferas do poder público ao CIF - órgão que reúne estados, municípios e Poder Executivo Federal com poder de fiscalização e sanção das políticas mitigatórias - e à Fundação Renova, criada especificamente para atender às demandas causadas pelo desastre ${ }^{6}$. 
Para analisar o resultado dessa estratégia para as políticas públicas de saúde nas cidades de Colatina e Linhares, indagamos: o que é considerado política pública de saúde pelo arranjo institucional proposto? Qual o papel de cada um dos atores na formulação e implementação das ações previstas e executadas? Consequentemente, cabe levantar quais foram os problemas de saúde enfrentados e as ações propostas, bem como a efetividade dessas ações. Por fim, considera-se a capacidade de accountability desse sistema, uma vez que a escuta dos atingidos é fundamental tanto na formulação como na implementação e, sobretudo, na avaliação. Em outras palavras, qual a capacidade desse arranjo ser monitorado e avaliado de forma continuada e eficaz?

\section{Metodologia}

Optamos por um desenho metodológico qualitativo, que associou análise de documentos e entrevistas semiestruturadas 7,8 . A pesquisa levantou documentos, enfocando os relatórios da Renova, divulgados no sítio virtual dessa organização (www.fundacaorenova.org), no período entre março de 2016, data da assinatura do TTAC, e maio 2018, data da coleta. Nos relatórios da Renova 9 , foram selecionadas todas as proposições e ações diretamente relacionadas com a saúde e com as cidades estudadas. Foram identificadas 35 ações, compreendidas aqui como a expressão pública da fundação sobre suas concepções, modos de agir e de se relacionar.

Essas ações foram classificadas em duas categorias amplas subdivididas em subcategorias (quadro 1). A primeira é 'Formato de ação', que se refere ao repertório de ação empregadas pela Fundação e foi criada a partir das categorias nativas, ou seja, aquelas usadas pela Renova nos seus relatórios, quais sejam: a) Preparativos para implementação; b) Implementação; c) Procedimento burocrático-administrativo; d) Procedimento Institucional; e) Reunião. A segunda categoria, 'Conteúdo de ação', foi construída com base no conceito de ciclo de políticas públicas que distingue cinco etapas: formação de agenda, especificação de alternativas, tomada de decisão, implementação e avaliação ${ }^{\mathbf{1 0}}$, adaptado ao caso e ao material (relatórios de prestação de contas) investigados. Ao aplicar esse crivo de análise, buscávamos entender em que etapas se encontrava a produção de ações de saúde, cujo escopo geral foi definido pelo TTAC. As subcategorias neste caso são: a) Especificação de alternativas; b) Busca de parceria; c) Contratação de terceiros; d) Diagnóstico; e) Entrega de produtos e serviços; f) Prestação de Contas. Mapeamos também os atores com quem a Renova se relacionou em cada uma das ações. Esses dados foram submetidos à análise de frequência e conteúdo. 
Quadro 1. Definições de categorias de análise utilizadas na análise dos relatórios da Renova

\begin{tabular}{|c|c|}
\hline Tipo de ação & Critérios de classificação \\
\hline Preparativos para implementação & $\begin{array}{l}\text { Ação que antecede a entrega de produtos e serviços propriamente dito, aqui en- } \\
\text { tendida como implementação. }\end{array}$ \\
\hline Implementação & Ação de entrega de produtos e serviços relacionada aos programas. \\
\hline $\begin{array}{l}\text { Procedimento burocrático-admi- } \\
\text { nistrativo }\end{array}$ & $\begin{array}{l}\text { Ação realizada pela Renova que faz parte de seus processos internos enquanto } \\
\text { Fundação. }\end{array}$ \\
\hline Procedimento Institucional & $\begin{array}{l}\text { Ação que a Renova realiza em função do ordenamento institucional do arranjo de } \\
\text { governança instituído no TTAC. }\end{array}$ \\
\hline Reunião & $\begin{array}{l}\text { Ação da Renova na qual a Fundação se relaciona com atores da sociedade civil } \\
\text { e comunidades (reunião a realização de workshop e apresentação de equipes de } \\
\text { trabalho para a comunidade, encontro com o objetivo de escuta/diálogo tendo em } \\
\text { vista o processo de tomada de decisão) }\end{array}$ \\
\hline \multicolumn{2}{|c|}{ Classificação dos relatórios conforme conteúdo da ação } \\
\hline Conteúdo da ação & Critérios de classificação \\
\hline \multirow[t]{2}{*}{ Especificação de alternativas } & $\begin{array}{l}\text { Ação que antecede a entrega de produtos e serviços propriamente dito, aqui en- } \\
\text { tendida como implementação. }\end{array}$ \\
\hline & Processo que implica a discussão e debate sobre as ações, programas e políticas. \\
\hline Busca de parceria & Ação que busca captar atores para trabalhar em conjunto com a Renova. \\
\hline Contratação de terceiro & $\begin{array}{l}\text { Ação para contratação e assinaturas de contratos com empresas, organizações da } \\
\text { sociedade civil ou governo. }\end{array}$ \\
\hline Diagnóstico & $\begin{array}{l}\text { Ação que visa à elaboração dos dados. Busca de evidências para estabelecimento } \\
\text { de nexo causal entre o desastre e o problema constatado. Levantamento de dados } \\
\text { e demandas, relatório ou estudo realizado, visitas técnicas realizadas para o fim de } \\
\text { levantar dados e fatos para subsidiar pareceres técnicos. }\end{array}$ \\
\hline Entrega de produtos e serviços & Ação que visa à entrega de produto ou serviço para o usuário final. \\
\hline Prestação de Contas & $\begin{array}{l}\text { Ação de prestação de informações e entrega de planos e projetos quando a Reno- } \\
\text { va foi cobrada para realizar tal ação. }\end{array}$ \\
\hline
\end{tabular}

Fonte: Elaboração própria.

Como método complementar e para entender de que forma as ações da Renova se relacionavam com o sistema público de saúde, foram realizadas sete entrevistas semiestruturadas, sendo três com gestores das Secretarias da Saúde de Linhares e de Colatina, uma entrevista com um conselheiro do Conselho Municipal de Saúde de Linhares e três entrevistas com técnicos do Instituto Estadual de Meio Ambiente que também participam das Câmaras Técnicas do CIF/Instituto Brasileiro do Meio Ambiente e dos Recursos Naturais Renováveis (Ibama) (não apresentaremos mais detalhes na caracterização para resguardar o anonimato dos entrevistados). O roteiro de entrevista enfocou as relações entre as políticas de saúde e os efeitos do desastre, explorando a participação de cada um dos atores envolvidos e as ações implementadas.

\section{A saúde dos atingidos após o rompimento da barragem}

O crime ambiental provocado pelo desastre da Samarco/Vale/BHP foi uma das piores tragédias ambientais da história, cuja recuperação levará décadas. Embora o número de mortes tenha sido baixo em comparação com o desastre de Brumadinho de 2019, os impactos para a saúde dos atingidos foram muitos:

a) comprometimento dos serviços de provisão de alimentos e água potável; b) de regulação 
do clima (destruição de mais de mil hectares de cobertura vegetal) e dos ciclos das águas (contribuindo para enchentes nos períodos chuvosos), contribuindo para alteração nos ciclos de vetores e de hospedeiros de doenças (dengue, chikungunya e zika, além de outras doenças como esquistossomose, doenças de Chagas, leishmaniose, que podem surgir meses após o período inicial do desastre); c) animais peçonhentos, que também tiveram seus habitats completamente alterados ou destruídos; d) doenças respiratórias e contaminação dos organismos com a transformação da lama de rejeitos em grande fonte de poeiras e material particulado (contendo óxido de ferro, sílica e matéria orgânica, além da hipótese de outros metais como alumínio e manganês) inalado pelas pessoas (14); e) impactos psicossociais e na saúde mental, resultantes do comprometimento das heranças culturais e da perda da sensação de lugar, bem como a sensação de insegurança e medo da violência para os que foram deslocados para abrigos ou casas temporárias, contribuindo para futuras doenças crônicas, como as cardiovasculares. Não menos grave foram também os impactos sobre os índios Krenak, que tiveram seus modos de vida, cultura e religião afetados pelo desastre $\mathbf{1 1 ( 2 7 )}^{\mathbf{1}}$

Como um efeito de longo prazo importante, Wanderley et al.12 apresentam estudos que relacionam a presença de metais pesados nos rios com o aumento das doenças crônicas e apontam a necessidade de acompanhamento e monitoramento por parte das políticas públicas. Neves et al. ${ }^{13}$ destacam os efeitos na saúde mental da população, como a ocorrência de estresse pós-traumático em $82 \%$ de crianças e adolescentes, risco de suicídio de 16,4\% nos atingidos, prevalência de depressão em $28,9 \%$ e transtorno de ansiedade generalizada em $32 \%$ dos entrevistados. Nota-se que os efeitos na saúde da população atingida não serão resolvidos em curto prazo e serão sentidos pelos indivíduos e comunidades por bastante tempo. Como argumentam Freitas et al. $^{14}$, para a saúde coletiva, é importante considerar a "emergência de novos problemas e necessidades de saúde ao longo do tempo, de modo que mobilizem quase toda estrutura de saúde pública"14(1).

Desse modo, as alterações no perfil epidemiológico da população e nas necessidades sociais em saúde provocadas pela situação de desastre vão exigir respostas do poder público nas políticas públicas de saúde no nível local e regional, considerando, sobretudo, efeitos de médio e longo prazo. Minimamente, devem ser fortalecidos os sistemas de atenção primária e vigilância em saúde, trabalhando de forma articulada e intersetorialmente com outras frentes de políticas públicas, dadas a complexidade e a intensidade dos problemas gerados. O contexto psicossocial demanda ações de promoção à saúde e educação popular que valorizem e reforcem os laços comunitários. Os serviços de atenção especializada devem ser ampliados para lidar com o aumento da demanda, mas também se preparar para buscas ativas e intervenções coletivas. As políticas públicas devem articular ações para atender às demandas em saúde, prevenindo as consequências de médio e longo prazo ${ }^{14}$. É importante que as informações sobre saúde pública estejam integradas à Defesa Civil e Ambiental15.

Essas prerrogativas do poder público deveriam ser consideradas e apoiadas pela Fundação Renova e pelo arranjo institucional criado para acompanhar, monitorar e avaliar sua atuação como executora de 'programas compensatórios e reparatórios'.

\section{Resultados e discussão}

\section{Descrição e problematização do arranjo institucional}

Desde o momento do desastre, a elaboração de medidas mitigadoras atravessou o estágio duplo de formulação, sendo o primeiro a elaboração de propostas por técnicos que compuseram um grupo interministerial (entre 
2015 e o início de 2016) e cujo resultado foi incorporado pelo TTAC. O segundo estágio diz respeito à elaboração de propostas pela Renova. O terceiro estágio se dá no interior do CIF, a quem cabe aprovar ou não as propostas elaboradas pela Renova, sempre consultando as Câmaras Técnicas que compõem órgãos responsáveis pela fiscalização da Renova por cada frente de ação.

A primeira etapa envolveu diversos órgãos da administração direta e indireta do Governo Federal, sob coordenação da Casa Civil da Presidência da República: Advocacia-Geral da União (AGU), Ministério do Desenvolvimento Social e Combate à Fome (MDS), Ministério do Desenvolvimento Agrário (MDA), Ministério da Agricultura, Pecuária e Abastecimento (Mapa), Ministério da Justiça (MJ), Secretaria de Governo da Presidência da República (Segov), Ministério da Saúde (MS), Ministério da Educação (MEC), Ministério da Cultura (MinC), Fundação Nacional do Índio (Funai) e Ibama. Pelo Poder Público, participaram também representantes dos Governos dos Estados de Minas Gerais (Secretaria de Desenvolvimento Regional, Política Urbana e Gestão Metropolitana) e do Espírito Santo (Secretaria de Saneamento, Habitação e Desenvolvimento Urbano).

Dessa reunião interministerial, surgiram diversos programas que, mais tarde, serviram como base para homologação do TTAC. O documento explicita as diretrizes definidas pela reunião, que contou com a participação do MS, e encaminha as seguintes determinações à Samarco/Fundação Renova:

Programa de apoio à saúde física e mental da população impactada: apoio para elaboração de protocolo de monitoramento da saúde da população exposta; apoio a Mariana e Barra Longa na execução de planos de saúde locais; desenvolvimento de estudo epidemiológico e toxicológico, de Mariana à foz do Rio Doce, para avaliar riscos decorrentes do evento; adoção de medidas mitigadora para garantir a saúde da população no caso de identificação de riscos ${ }^{5(134)}$.
O TTAC foi assinado em 2 de março de 2016 e homologado em 5 de maio seguinte pela Justiça Federal. Da data da propositura da ação civil pública (30 de novembro de 2015) até a assinatura do TTAC decorreram apenas três meses. Este foi o tempo em que perduraram as negociações acerca dos termos previstos no TTAC. Tendo em vista que esse prazo não seria suficiente para que se pudesse caracterizar, com precisão, a real dimensão dos danos ambientais e socioeconômicos produzidos pelo desastre, as partes signatárias optaram por redigir um TTAC com cláusulas genéricas e indeterminadas. Observa-se que o apoio à 'execução de planos de saúde locais' foi restrito a Mariana e Barra Longa, e outras medidas deveriam ser adotadas em 'caso de identificação de riscos', o que depende de estudos e avaliações que podem demorar e não têm prazo estipulado para realização.

Não obstante a falta de diagnóstico prévio capaz de oferecer informações seguras que subsidiassem a formulação detalhada das medidas de reparação, remediação, compensação e indenização a serem adotadas, o TTAC estabeleceu limites para a alocação de recursos a certas categorias de ações. Além de estabelecer que os programas socioeconômicos de natureza reparatória teriam prioridade sobre os demais programas, o TTAC estabeleceu uma quantia fixa anual para dispêndio com medidas de natureza compensatória. Na lógica estabelecida no TTAC, não será possível alocar recursos superiores a $\mathrm{R} \$ 240$ milhões anuais para ações compensatórias, ainda que estas se revelem necessárias. $\mathrm{O}$ termo ainda determinou que a empresa tem 15 anos para realizar todas os programas de mitigação.

No período abrangido pela pesquisa (março de 2016 a maio de 2018), O TTAC está em vigor, e o sistema CIF está operando. A Câmara Técnica (CT) de Saúde, encarregada de fiscalizar as ações da Renova nesse setor, foi criada apenas em 9 de maio de 2017. Em 12 de dezembro de 2017, a Fundação Renova entregou um Relatório que tem como finalidade 'formalizar as entregas da fase de definição do Programa 
de Apoio à Saúde Física e Mental da População Impactada de acordo com Termo de Transação e de Ajustamento de Conduta (TTAC - cláusulas 106 a 112)'. Nele, a Renova indica o que já cumpriu - fala do foco nas ações emergenciais - e descreve o planejamento para os anos seguintes. Em torno de três meses depois (23 de março de 2018), o coordenador da CT de Saúde envia um ofício do Secretário Executivo do CIF apontando que o tal Relatório da Renova não está fazendo referências ao Sistema Único de Saúde (SUS) e a seus padrões, além de diversas outras críticas. Em 10 de maio, a CT rejeita o relatório, apontando diversas insuficiências, entre as quais, falta de detalhamento de planos, documentos e resultados. Esse é o plano de interações entre a Fundação e o sistema CIF no qual se inserem as ações realizadas pela Renova a serem analisadas a seguir.

\section{Como são produzidas e implementadas as políticas de recuperação?}

Como já explicitado, os efeitos do desastre causado pelo rompimento de barragem pertencente à empresa Samarco, na cidade de Mariana (MG), seriam reparados e/ou compensados por meio de programas executados pela Fundação Renova, controlada pelas empresas e pelo novo órgão intergovernamental: o CIF do qual fazem parte os Comitês Técnicos setoriais. Esse arranjo institucional, ou modelo de governança, foi criado para dar conta da produção de decisões, da busca de alternativas, da implementação de ações concretas para compensar ou reparar os danos causados pelo desastre bem como da sua fiscalização. Ainda que seja controverso chamarmos essas ações de 'políticas públicas', o desastre passou a ocupar a agenda do Estado por meio do TTAC, sendo tratado como problema público e objeto de ações para reparação e compensação que entraram ou deveriam entrar na agenda de implementação de atores privados e públicos. Estes últimos foram incumbidos não só de monitorar e fiscalizar, mas também de aprovar os planos de ação. Além disso, o que é mais importante, por ações concretas, estavam e estão esperando milhares de pessoas nomeadas de 'atingidas'. Cidadãos e, portanto, portadores de direitos.

Assim, o conjunto de ações que recortamos podem ser analisados pela lente do ciclo de políticas públicas em uma perspectiva multicêntrica ${ }^{10}$. A atuação da Renova e do CIF são parte da estrutura de implementação de ações em saúde para sanear problemas decorrentes do desastre. Das seis etapas do ciclo, as duas primeiras (identificação do problema e formação de agenda) foram definidas após o rompimento da barragem com a assinatura do TTAC. As outras quatro fases (especificação de alternativas, decisão, implementação, avaliação e monitoramento) seguirão em tensionamento do arranjo institucional, tendo a atuação da Renova como foco, pois o TTAC não especificou suficientemente as ações a serem implementadas e apenas prevê que a Fundação elabore e submeta seus planos de ação para a aprovação e avaliação do CIF. É necessário ressaltar que o ciclo e suas etapas não podem ser vistos de forma mecânica e linear. As etapas podem se repetir dentro do mesmo ciclo, se sobrepor ou o próprio ciclo pode se dar mais de uma vez dentro de uma mesma política, mas esse fluxo de processos em cascata não impede destacar os atores relevantes e as características de cada etapa ${ }^{10}$.

A análise da especificação de alternativas, momento em que se elaboram soluções para que, a partir de critérios técnicos e políticos, tomem-se decisões ${ }^{\mathbf{1 6}, 17}$, ajuda-nos a identificar quem apresentou, elaborou ou participou das soluções apresentadas pela Renova. As secretarias municipais de saúde das cidades aqui estudadas (Linhares e Colatina) fizeram parte da elaboração das soluções? Os atingidos foram consultados? Quanto tempo durou o processo de tomada de decisão? Se a etapa da decisão se caracteriza por ser restrita aos tomadores de decisão incumbidos, aqui vale a pena indagar se, fora do CIF, os conselhos das empresas desempenhavam algum papel de veto, retardando o processo. A etapa da 
implementação, por sua vez, está longe de ser a mera execução de ordens advindas de cima. Ou pode ser exatamente isso, mas com todas as imperfeições já detectadas pela literatura ${ }^{\mathbf{1 8}}$. Os autores que lidam com a implementação também indicam que, na sua execução, podem aparecer configurações distintas de atores entre os públicos, privados, com e sem fins lucrativos; e essas configurações terão efeitos distintos em termos de efetividade na entrega das ações ${ }^{19}$. Essa síntese de traços particulares da etapa da implementação nos leva a questionar sobre a composição da estrutura da implementação e sobre a efetividade da entrega de produtos e serviços.

\section{Produção de ações de saúde após o rompimento da barragem}

O TTAC, da cláusula 106 a 113, designa à Fundação Renova desenvolver atividades de apoio à saúde física e mental dos impactados e elaborar um estudo epidemiológico e toxicológico para identificar o perfil epidemiológico e sanitário retrospectivo, atual e prospectivo dos moradores de Mariana até a foz do Rio Doce, a fim de avaliar riscos e correlações decorrentes do rompimento ${ }^{5}$. Para as ações em saúde, a Renova dispõe de $\mathrm{R} \$ 128$ milhões a serem investidos ao longo de dez anos a partir da data do desastre. A análise das atividades dos relatórios da Renova relacionados com a 'saúde' nos primeiros 30 meses após o rompimento mostra que a especificação de alternativas, isto é, busca de soluções para os problemas identificados, correspondia a $40 \%$ do total de ações (tabela 1). Em segundo lugar, a Renova relata suas ações como elaboração de diagnósticos que abrangiam 31,4\% do total. Um exemplo desse tipo de 'ação em saúde' é a 'visita técnica' da Renova às lideranças das comunidades de Regência e Povoação com o intuito de levantar dados e fatos para subsidiar parecer técnico. Em terceiro lugar, a Fundação dispensou o seu tempo em busca de parcerias e de contratação de terceiros que somam conjuntamente quase $23 \%$. A categoria de entrega de serviços aos usuários foi mencionada apenas uma vez. Se a elaboração de diagnósticos corresponde ao esperado pela atribuição contida no TTAC, a parte que determinava o apoio à saúde física e mental encontrava-se, claramente, na fase de definições.

Tabela 1. Conteúdo de ações desenvolvidas pela Renova na saúde (03/2016 a 05/2018)

\begin{tabular}{lrr}
\hline Conteúdo das ações & Frequência & Percentual \\
\hline Especificação de alternativas & 14 & 40,0 \\
Busca de Parceria & 4 & 11,4 \\
Contratação de Terceiros & 4 & 11,4 \\
Diagnóstico & 11 & 31,4 \\
Prestação de contas & 2 & 5,7 \\
Entrega de produtos e serviços & 1 & 2,8 \\
Total & 36 & 100 \\
\hline
\end{tabular}

Fonte: Elaboração própria com base nos relatórios da Fundação Renovaํ․ 
Analisamos as mesmas ações pelo crivo da forma, isto é, buscando entender de que maneira a Fundação se organiza, como procede e como age para executar os programas previstos (tabela 2). As formas corroboram a análise anterior que indica a predominância da especificação de alternativas em termos de conteúdo ao mostrar que a Renova promoveu naquele tempo com bastante intensidade as reuniões (13 do total de 36), entre as quais encontram-se as com comunidades atingidas. Esse dado pode ser interpretado de duas maneiras distintas. Se, por um lado, evidencia a existência desses contatos, percebe-se que a Fundação não elaborou nenhuma forma específica no seu repertório de ação para nomear as relações sistemáticas com os atingidos e torná-las uma linha de ação específica. Por outro, dada a complexidade das ações a serem realizadas e as redes de relações que a empresa precisou construir para executar o programa de mitigação da saúde, fica evidente a necessidade do contínuo fluxo de aproximação e deliberação com outros atores sejam eles sociais ou estatais. Entre outras formas mais frequentes, destaca-se o envolvimento da Renova de forma equânime em procedimentos burocrático/administrativos que dizem respeito ao próprio funcionamento da Fundação e em relação às exigências do CIF que aparecem na categoria de procedimento institucional, 11 e 9 respectivamente.

Tabela 2. Repertório de ação da Renova relacionado com a saúde (03/2016 a 05/2018)

\begin{tabular}{lrr}
\hline Tipo de ação & Frequência & Percentual \\
\hline Implementação & 1 & 2,7 \\
Preparativos para implementação & 2 & 5,5 \\
Procedimento burocrático/administrativo & 11 & 30,5 \\
Procedimento Institucional & 9 & 25 \\
Reunião & 13 & 36,3 \\
Total & 36 & 100 \\
\hline
\end{tabular}

Fonte: Elaboração própria com base nos relatórios da Fundação Renova9

O terceiro crivo de análise passa pela pergunta sobre os atores com que a Renova se relacionou. Tendo em vista os dados anteriores, não surpreende que $70 \%$ de suas ações se deram com os atores do Estado, primordialmente o CIF, por força legal do TTAC. Isso ocorre porque a entidade não tem autonomia para tomada de decisões e precisa, com frequência, prestar contas de seus movimentos ao órgão. Além do CIF, a Renova se relacionou com outros atores estatais, entre eles, ainda que apenas ocasionalmente, com as secretarias municipais de saúde. Ainda que esteja disposto no TTAC que a sociedade fosse ouvida e as ações fossem construídas de forma participativa, os relatórios da Fundação não indicam esse movimento. As entidades da sociedade civil organizada são as que ocupam o último lugar em número de vezes que foram mencionados nos relatórios, em comparação com os atores institucionais.

Em suma, o conjunto de dados aqui apresentados dão maior força à argumentação de que a Fundação, entre março de 2016 e maio de 2018, encontrava-se ainda no estágio de formulação e distante de apresentar efetividade em suas ações reparatórias no que se refere à saúde. Diante da escassez de efetivas políticas mitigadoras, no que tange à saúde dos atingidos, constatadas desde a análise 
dos relatórios mensais da Fundação Renova, recorremos, então, às entrevistas com agentes públicos, que atuam nas cidades de Colatina e Linhares. O intuito dessa etapa da pesquisa era, mais uma vez, entender como se articularam os atores envolvidos no processo, Renova, Ibama, estado e municípios, na busca por respostas aos prejuízos causados pela lama na saúde da população atingida.

Os agentes públicos declaram descontentamento com o arranjo institucional criado para mitigar os prejuízos da lama, seja com relatos críticos à execução do processo burocrático determinado por meio do TTAC, seja pelas dificuldades de acesso e fiscalização da Fundação Renova. Uma trabalhadora da saúde afirma que, até o mês de março de 2019, a execução de políticas públicas fora feita apenas pelo poder municipal:

Até hoje, só a nós mesmos. Renova só aparece aqui para aplicar questionários. Governo do Estado ajuda com questões mais burocráticas, então, no fim, tudo acaba com a Prefeitura. Com os atendentes de posto, com o médico da UBS, com agentes de saúde, enfim, com a ponta do sistema. A gente faz o que pode, mas é muito complicado.

Uma assistente social também relata que o município tem sido o maior indutor das políticas, sem contar com o auxílio dos demais atores:

Dentro dos nossos limites humanos e financeiros, fazemos tudo aquilo que a gente pode. Tudo! Mas nossa gama de ações é limitada e, inclusive, já está desgastada. A gente recorre às outras secretarias, ao prefeito, ao pessoal daqui mesmo. Governo do Estado auxilia naquilo que é pactuado, nada extra. A Renova? Foge da gente. Criou uma fundação para não cumprir o papel de auxiliar as pessoas.

A descrença das servidoras não fica restrita à Fundação, mas também às instituições criadas a partir do TTAC (o CIF e as CTs). De acordo com uma enfermeira, "não produzem as respostas esperadas". No mesmo sentido, a assistente social argumenta que o novo arranjo é improdutivo: "A gente luta, luta, luta, chega na hora de concretizar as ações, lá dentro do CIF mesmo, e não dá em nada. É tudo difícil".

Para além dos problemas de relação do novo arranjo institucional, há também disputas de interesse. Uma trabalhadora da saúde, representante da secretaria de saúde de um dos municípios no CIF, expressa essa problemática:

Tem muito interesse dentro desse esquema todo, interesse político e financeiro. Se eles resolvessem o problema de falta de transparência, já ia ajudar muito.

Apesar do diagnóstico ter sido uma das ações implementadas pela Renova, os entrevistados ligados ao setor municipal de saúde não têm conhecimento sobre quais são as doenças causadas pelo desastre e quais são naturais, e argumentam que este é um tema de discordância e conflito entre os atores envolvidos. Ao mesmo tempo, a construção do arranjo institucional do CIF com suas Câmaras mostra certa lentidão nas idas e vindas entre documentos produzidos e emitidos entre a Renova e as instâncias fiscalizadoras.

Em ambas as cidades, tanto o Poder Público quanto a empresa ainda não haviam realizados estudos adequados sobre o impacto à saúde dos atingidos nas cidades do estado do Espírito Santo. Sem a elaboração de exames que demonstrem o aparecimento de doenças, não há como produzir e estabelecer políticas públicas efetivas. Isso já demonstra a perspectiva de 'saúde' associada à ausência de doenças, que é insuficiente para mitigar os efeitos de longo prazo. Ao mesmo tempo, duas enfermeiras e uma assistente social foram enfáticas em identificar o aumento de problemas de saúde, físicos e psicológicos, nos serviços.

No período analisado, não identificamos nos dados qualquer interação com os equipamentos, diretrizes e políticas formuladas pelo SUS. As políticas de saúde instituídas e consolidadas nos territórios, que foram sobrecarregadas e não receberam aportes para qualificação ou potencialização, não foram citadas nos relatórios da Renova. Identifica-se pouca afinidade 
das proposições com o arcabouço institucional do SUS, e não houve reforço, ampliação ou qualificação da rede de saúde local para atender a população.

Isso nos pareceu um dado importante para nossas perguntas da introdução, pois são desconsideradas as políticas públicas de saúde instituídas, bem como os atores que a executam. Identificamos que Renova se relaciona preferencialmente com atores estatais, mas não com atores que estão na ponta das políticas públicas. A maior frequência de ações, como 'reuniões' e procedimentos burocráticos, questiona a efetividade do que foi realizado pela saúde dos atingidos, ao mesmo tempo que nos leva a identificar uma perspectiva pouco participativa.

A ausência de conexões das ações previstas com as políticas públicas de saúde nos leva a criticar a concepção subjacente de política pública presente no arcabouço institucional que produziu o arranjo analisado. De acordo com o TTAC, caberá à Fundação o apoio técnico para atendimento das prefeituras e das ações a serem executadas pela Fundação Renova, mas não foi prevista nenhuma articulação entre atenção primária e vigilância em saúde, tampouco com Defesa Civil e ambiental ou assistência social, para pensar nos efeitos de médio e longo prazo. Como se colocam atores privados para responder a problemas públicos sem negociar com as instâncias estabelecidas de saúde? Uma concepção na qual se terceirizam os agentes executores das ações mitigadoras, sem que estes sejam alvo de arranjos que promovam a participação e o controle social, reduzindo a capacidade de accountability do sistema, como revela a fala de algumas entrevistadas. As instâncias de controle social já instituídas, tais como os Conselhos Municipais de Saúde, sequer participam das discussões no âmbito do arranjo aqui estudado, ao mesmo tempo que nossos entrevistados reclamam da falta de transparência no processo.

Em síntese, nota-se que o arranjo institucional gerou uma estrutura político-administrativa formulada de forma nitidamente top down, que reforçou a etapa de formulação de políticas em detrimento da implementação e sem articular os atores engajados, quer sejam do SUS, quer sejam da sociedade civil.

\section{Considerações finais}

Os dados analisados nos levam a considerar que as ações de saúde para a mitigação dos problemas decorridos do desastre na região de Linhares e Colatina são incipientes e desarticuladas das necessidades específicas do campo da saúde, sobretudo os efeitos de médio e longo prazo, que se relacionam diretamente às desigualdades sociais e à constituição das comunidades. Três anos após o rompimento da barragem, as secretarias municipais de saúde não tinham dados fidedignos sobre os impactos causados na saúde e nenhum plano articulado de ações. A baixa capacidade de execução e o inexistente papel das instâncias participativas para produzir algum efeito no processo decisório foram pontos frágeis do arranjo proposto.

Argumenta-se que uma das razões pela baixa efetividade é o grau de generalidade das ações especificadas no TTAC e pelo fato de a CIF não ter caráter propositivo, mas reativo. No caso da saúde, acrescenta-se que uma das razões pela baixa efetividade é a não inclusão do SUS como parte das ações propostas; o qual poderia ter sua infraestrutura potencializada, qualificada e/ou ampliada, ou pelo menos ser considerado na articulação com outros atores, evitando desperdício de recursos e a sinergia nas ações.

A ausência do SUS e de medidas de fortalecimento da estrutura em funcionamento na rede de saúde pode ser vista como uma cultura política que desvaloriza as políticas públicas, pois não considera o acúmulo e a capacidade de resolutividade desse sistema como relevante para o enfrentamento das consequências do desastre. Por outro lado, os entrevistados ligados às secretarias de saúde indicam a sobrecarga no sistema na atenção aos problemas de saúde, que aumentaram com o desastre. 
É importante destacar que os problemas gerados por esse modelo seriam dirimidos pelos princípios doutrinários e organizativos do SUS. Os princípios doutrinários - universalidade, integralidade e equidade - agregariam a esse arranjo sensibilidade social e abrangência estratégica para abordar o impacto das desigualdades, as necessidades sociais em saúde e a complexidade dos processos saúde-doença. Os princípios organizativos - regionalização e hierarquização, descentralização, comando único e participação social - alertariam para a importância da organização dos serviços em níveis de complexidade, planejamento a partir de critérios epidemiológicos (articulando atenção primária e vigilância em saúde) que caracterizem adequadamente a população atendida. Isso aponta para a articulação entre os serviços existentes e a pactuação entre atores para garantir recursos e capacidade técnica e política para a efetiva execução de ações em saúde. A participação social, princípio constitutivo do SUS, aproxima os atores envolvidos, qualifica as práticas em saúde e aumenta a capacidade de accountability. Todos estes princípios estão relacionados com problemas críticos do modelo analisado.

A partir de junho de 2018, um mês depois da data limite da coleta dos dados desta pesquisa portanto, o arranjo institucional e os acordos sofrerem importantes mudanças que visavam sanear os problemas identificados inclusive por esta investigação. Em junho, foi assinado o TTAC de governança que criou formatos para a efetiva e constante participação das comunidades atingidas no arranjo institucional CIF-Renova. A CT de Saúde emitiu a Nota $\mathrm{n}^{\mathrm{o}} 4$, na qual estabeleceu que a Renova devesse estabelecer um subprograma de apoio e fortalecimento ao SUS; e, em outubro de 2018 ainda, publicou uma outra determinando que os munícipios atingidos devessem elaborar Planos de Ação de Saúde a serem apoiados e fortalecidos pela Fundação. Ambas as notas foram aprovadas pelo CIF. Com isso, os diagnósticos e prognósticos locais seriam elaborados pelas secretarias municipais de saúde e por suas comunidades. O processo avançou pouco, com apenas um município apresentando o Plano até junho de 2019. Assim, a Defensoria Pública e o Ministério Público de Espírito Santo promoveram um encontro para comprometer os municípios com tais planos; e, juntamente com a Defensoria Pública da União e com o Ministério Público Federal, emitiram uma recomendação a municípios que ainda não haviam se posicionado.

Por meio dessas ações, percebe-se a paulatina incorporação do SUS, suas diretrizes e princípios, bem como dos seus agentes ao arranjo institucional. Ainda estão por serem pesquisados os efeitos da reparação dos prejuízos causados pelo rompimento da barragem da Samarco à saúde, mas está claro que o primeiro desenho que apartou o SUS e as comunidades atingidas dos programas elaborados no TTAC e a serem implementados pela Renova não foi efetivo ao menos no que se refere às ações de saúde no Espírito Santo nos primeiros 30 meses após o rompimento da barragem. Arranjos compostos por atores com competências setoriais e de gestão permeados pela voz da comunidade parecem ser bastante promissores para que os direitos sociais possam ser cumpridos a tempo e ao longo do tempo.

\section{Colaboradores}

Machado FV (0000-0002-8884-1124)*, Dowbor MW (0000-0002-1845-046X)*, Amaral I (0000-0001-7884-7808)* contribuíram igualmente para a elaboração do manuscrito. 


\section{Referências}

1. Londe LR, Marchezini V, Conceição R, et al. Impactos de desastres socioambientais em saúde pública. R. bras. Est. Pop. 2015; 32(3):537-562.

2. Freitas CM, Silva DRX, Sena ARM, et al. Desastres naturais e saúde: uma análise da situação do Brasil. Ciênc. Saúde Colet. [internet]. 2014 [acesso em 2019 set 29]; 19(9):3645-3656. Disponível em: http:// dx.doi.org/10.1590/1413-81232014199.00732014.

3. Organização Pan-Americana da Saúde; Ministério da Saúde. Desastres naturais e saúde no Brasil. Brasília, DF: Opas; Ministério da Saúde; 2014 (Série Desenvolvimento Sustentável e Saúde. v. 2).

4. Organização Pan-Americana da Saúde. Protección de las nuevas instalaciones de salud frente a desastres naturales: guía para la promoción de la mitigación de desastres. Washington, DC: Opas; Banco Mundial; 2003.

5. Instituto Brasileiro de Meio Ambiente e dos Recursos Naturais Renováveis; Instituto Chico Mendes de Conservação da Biodiversidade. Termo de Transação e de Ajustamento de Conduta. Brasília, DF: ICMBio; 2016.

6. Instituto Brasileiro de Meio Ambiente e dos Recursos Naturais Renováveis. Regimento Interno do Comitê Interfederativo. Brasília, DF: Ibama; 2016.

7. Creswell J. Research Design: Qualitative, Quantitative, and Mixed Methods Approaches. London: SAGE; 2003.

8. Minayo MCS. O desafio do conhecimento: pesquisa qualitativa em saúde. 8. ed. São Paulo; Rio de Janeiro: Hucitec; Abrasco; 2004.

9. Fundação Renova. Relatórios mensais [internet]. 2016-2018. [acesso em 2019 jun 23]. Disponível em: https://www.fundacaorenova.org/wp-content/uploads.

10. Secchi L. Políticas Públicas: conceitos, esquemas de análise, casos práticos. São Paulo: Cengage Learning; 2013.

11. Freitas CM, Silva MA, Menezes FC. O desastre na barragem de mineração da Samarco: fratura exposta dos limites do Brasil na redução de risco de desastres. Cienc. Cult. [internet]. 2016 [acesso em 2019 set 29]; 68(3):25-30. Disponível em: http:// dx.doi.org/10.21800/2317-66602016000300010.

12. Wanderley LJ, Mansur MS, Milanez B, et al. Desastre da Samarco/Vale/BHP no Vale do Rio Doce: aspectos econômicos, políticos e socio ambientais. Cienc. Cult. [internet]. 2016 [acesso em 2019 set 29]; 68(3):30-35. Disponível em: http://dx.doi. org/10.21800/2317-66602016000300011.

13. Neves MGL, Roque M, Freitas AA, et al. PRISMMA. Pesquisa sobre a saúde mental das famílias atingidas pelo rompimento da barragem de Fundão em Mariana. Belo Horizonte: Corpus; 2018.

14. Freitas CM, Barcellos C, Asmus CIRF, et al. Da Samarco em Mariana à Vale em Brumadinho: desastres em barragens de mineração e Saúde Coletiva. Cad. Saúde Pública [internet]. 2019 [acesso em 2019 set 29]; 35(5):e00052519. Disponível em: http://dx.doi.org/10.1590/0102-311x00052519.

15. Sobral A, Freitas CM, Andrade EV, et al. Desastres naturais - sistemas de informação e vigilância: uma revisão da literatura. Epidemiol. Serv. Saúde. 2010; 19(4):389-402.

16. Kingdon JW. Agendas, alternatives and public policies. New York: Harper Collins; 1995.

17. Capella ACN. Formulação: o processo de defini- 
ção de alternativas. In: Capella ACN. Formulação de Políticas. Brasília, DF: ENAP; 2018. p. 71-108.

18. Hogwood B, Gunn L. Why "perfect implementation" is unattainable. The policy process. reader. 1993; (2):217-25.

19. Hjern B, Porter DO. Implementation structures: A new unit of administrative analysis. In: Holzner
B, Knorr KD, Strasser H. Realizing social science knowledge. Heidelberg: Physica, Heidelberg; 1983.

p. 265-277.

Recebido em 30/09/2019

Aprovado em 08/04/2020

Conflito de interesses: inexistente

Suporte financeiro: Coordenação de Aperfeiçoamento de

Pessoal de Nível Superior (Capes), Edital 'Redes de Pesquisa para Recuperação da Bacia do Rio Doce' e Conselho Nacional de Desenvolvimento Científico e Tecnológico (CNPq) 